\title{
PARATOPIA, AUTORALIDADE TEOLÓGICA E HIPERENUNCIADOR
}

Jarbas Vargas NASCIMENTO

\section{Introdução}

Este capítulo faz parte de uma pesquisa maior que vimos desenvolvendo sobre o discurso teológico, a partir do questionamento da hipótese proposta por Maingueneau \& Cossutta (1995) e continuada por Maingueneau (1995a, 1995b, 1996, 1999, 2000, 2005, 2007, 2008, 2009, 2010, 2012, 2015a, 2015b, 2015c, 2018) sobre a categoria discursos constituintes e de paratopia, condição desse tipo de discurso. Construída pelo próprio discurso, a paratopia pode ser compreendida como uma impossibilidade de a autoridade enunciativa atribuir a si mesma uma posição criadora, que legitime seu real pertencimento discursivo. Para compreendermos melhor essa categoria hipotetizada por Maingueneau \& Cossutta (1995), julgamos necessário apresentá-la como a condição de pertencimento/não-pertencimento de uma instância autoral, essencial ao discurso teológico e a todos os discursos constituintes. 
O próprio Maingueneau (2000), aqui e em outros momentos, desenvolvendo seus estudos sobre discursos constituintes, adverte-nos que se trata de um programa inicial de pesquisa; no entanto, de partida, ele enquadra na categoria dos constituintes, os discursos literário, filosófico, científico e o religioso. Como esses discursos, segundo o autor, legitimam sua própria origem, eles acionam e dão existência a todos os outros tipos de discurso. A lógica que leva Maingueneau a agrupar esses discursos se fundamenta na atividade criadora de seus produtores, uma vez que elaboram discursos-limite, que são, simultaneamente, auto e heteroconstituintes e cuja instauração se funda na condição paratópica de seu próprio ato de criação.

Essas pressuposições teóricas postuladas por Maingueneau (2000, 2008, 2010), dada a relevância para os estudos do discurso, motivou-nos a abordar, nesse capítulo, a paratopia relacionada ao produtor do discurso teológico, colocando-a em sua complexa vinculação com o hiperenunciador, instância que garante a unidade e a validade dos enunciados do Thesaurus (MAINGUENEAU, 2005). Além disso, o criador do discurso teológico é invocado pela inspiração divina e instaura um hiperenunciador, engendrado pela/na enunciação teológica, concebido como um sujeito integrador e absoluto, que dá sustentação ao Thesaurus bíblico. Embora seja uma categoria muito importante no âmbito da enunciação teológica, os estudos discursivos ainda não propuseram maiores aprofundamentos sobre o hiperenunciador, apesar de sua urgência nas discussões sobre enunciação. Como o hiperenunciador ocupa uma posição primordial na cenografia teológica, ele assume uma posição discursiva humana/divina, que estabelece, no discurso, uma condição paratópica, que lhe confere autoridade e valida sua posição de fonte absoluta dos efeitos de sentido. Nessa perspectiva, o criador do discurso constituinte teológico, ao mobilizar os conhecimentos linguístico-religiosos e histórico-culturais da socie- 
dade onde vive, expressa uma condição paratópica, na medida em que é interpelado a evidenciar, assimilar e integrar, na enunciação, um hiperenunciador, reconhecido como um sujeito individuado (MAINGUENEAU, 2005).

Por conta desse intricado processo enunciativo-discursivo, elegemos para apoio teórico-metodológico a Análise do Discurso de linha francesa $(\mathrm{AD})$, na perspectiva proposta por Maingueneau $(2005,2010,2014,2018)$ em diálogo com Cossutta (1994) e com os estudos do filósofo Foucault (2002) sobre a autoria. É necessário dizer que, mesmo com uma existência extradiscursiva, é no interior do discurso que autor se inscreve na cenografia, comprovando por meio de marcas textuais sua presença. No entanto, como lidamos com o discurso constituinte teológico e com a paratopia, uma hierarquia essencialmente superior se impõe pela voz que assume o hiperenunciador nesse tipo de discurso. A escolha que fazemos pela $\mathrm{AD}$ e por esse constructo teórico-metodológico se justifica pelas motivações, que essa disciplina suscita e pelo modo como ela se configura para um estudo interdisciplinar sobre a natureza da linguagem e sua relação com a Teologia, como esse estudo se descortina.

Vale dizer que os estudos discursivos, na perspectiva que adotamos, permitem-nos posicionamentos críticos e a proposição de novas hipóteses de pesquisa no tratamento de seus objetos de investigação, particularmente, do discurso teológico. Para nós, o avanço epistemológico dos estudos em $\mathrm{AD}$ parece-nos uma possibilidade metodológica ímpar para a pesquisa sobre o discurso teológico.

A análise do discurso é uma perspectiva radicalmente nova que tem implicações sobre o conjunto das questões psicossociológicas [...] os outros métodos se recusam a 
levar em conta ou mascaram o caráter ativo, construtor do uso da linguagem na vida cotidiana (POTTER \& WETHERELL, apud MAINGUENEAU, 2015a, p. 29).

É necessário afirmar, contudo, que é inegável a contribuição da Exegese, da Hermenêutica e da Crítica Literária, na medida em que cada uma dessas disciplinas evidencia seus procedimentos metodológicos no processo de aprimoramento da interpretação e aprofundamento dos textos bíblicos. Vale dizer, ainda, que sabemos que estudo da linguagem não deve se restringir somente aos linguistas, cujo domínio também é limitado (CULIOLI, 1999).

Nosso objetivo é examinar a paratopia no discurso teológico e a problemática relação entre o sujeito criador e o sujeito hiperenunciador que, na cenografia, alimenta sua inclusão e negocia um espaço de pertencimento/não pertencimento ao discurso. Embora possamos distinguir diferentes representações da paratopia, para Maingueneau (2008), ela envolve, no mínimo, o pertencimento e o não pertencimento e a inclusão impossível numa topia. O criador do discurso teológico encena a função daquele que onde está/ não está, daquele que vai de lugar a lugar, sem desejar fixar-se, ou daquele que não encontra lugar. $\mathrm{O}$ autor evoca as manifestações enunciativas, dá vestígios de seu processo criativo, mas o hiperenunciador, ao movimentar-se na encenação teológica, neutraliza a função autoral e garante a unidade textual, criando uma espécie de paradoxo espacial (MAINGUENEAU, 2008).

O criador do discurso teológico constrói enunciados relacionados à sua condição de exercício de vida, no interior da comunidade discursiva de sua época, sem possibilidade de, na enunciação, atribuí-los para si, principalmente porque a inspiração divina concede indiscutível autoridade a esse tipo de texto ${ }^{1}$. Nesse contexto,

1 “Toda a escritura é divinamente inspirada [...]" (2a Tm 3:16, grifo nosso). 
sublinhamos que o estudo aqui proposto visa a verificar, especificamente, o modo como o evangelista cria o texto, inscreve o enunciador e introduz o hiperenunciador, que referenda, particulariza e constitui-se sujeito central, na enunciação teológica, ao interferir no processo criativo e incorporar-se na organização do discurso. Por isso, com uma perspectiva de reflexão e análise, nosso estudo se insere no campo da Linguística e opera na interdiscursividade com o campo da Teologia.

O caráter interdisciplinar e seu modo crítico de assumir o discurso são o lado forte da $\mathrm{AD}$, posto que viabiliza estudos, que entrelaçam diferentes epistemologias. Como a linguagem constitui um dispositivo de aprofundamento da discursividade, apreendemos a $\mathrm{AD}$, estabelecendo diálogos abertos, debates e investigações, que ultrapassam as fronteiras da Linguística.

O próprio postulado dos estudos sobre o discurso, a saber, que todo e qualquer tipo de produção verbal é digno de investigação, já possui por corolário a raridade dos objetos efetivamente estudados, em relação ao infinito de corpus possíveis. São inevitavelmente os fenômenos sociais percebidos como importantes - seja a que título for - que retêm mais facilmente a atenção e que recebem as melhores subvenções. A isso acrescenta-se o fato de que a pluri, a trans, a interdisciplinaridade são hoje largamente recomendadas pelas politicas de pesquisa, tornando-se com frequência a condição sine qua non de obtenção de créditos. Nesses «territórios», o estudo do discurso não é senão uma das abordagens possíveis ao lado de outras, vindas de outros horizontes das ciências humanas e sociais (MAINGUENEAU, 2007, p. 16). 
O corpus que analisamos é o discurso da multiplicação dos pães e dos peixes, materializado nos evangelhos sinóticos, visando a identificar como a Teologia institui uma cena englobante, que produz uma cenografia construída por um enunciador, que representa o escritor, que negocia seu lugar com uma instância absoluta, que circula entre o pertencimento e o não-pertencimento ao discurso e à comunidade discursiva. Ainda que, nosso empreendimento analítico se delimite aos escritores de evangelho, vale ressaltar que a escolha desse grupo de produtores serve apenas como uma referência pois, com efeito, identidade criadora idêntica cabe a todos os outros autores dos livros do Primeiro e do Segundo Testamentos. É preciso acrescentar, ainda, que os quatro evangelhos, escritos por Mateus, Marcos, Lucas e João, constituem o núcleo do Segundo Testamento e comprovam a tradição apostólica da vida e da palavra de Jesus Cristo (PRIOTTO, 2019).

Observamos, nessas considerações iniciais, a complexidade da tarefa a que nos dedicamos; sabemos, entretanto, das limitações que ela nos impõe, bem como a necessidade de uma abordagem mais ampla, que amplie a leitura e análise dos textos teológicos. Um entendimento claro do que estamos propondo só se torna, realmente, possível em uma perspectiva, que considere o autor teológico como aquele que assume a função de apresentar-se a si por meio de um código linguageiro, que o particularize como escritor, mas que a ele implique uma condição de ser e não ser o criador de seu próprio discurso.

Enfim, organizamos esse capítulo em três tópicos: o primeiro em que contextualizamos o debate, o segundo, os pressupostos teórico-metodológicos, em que tratamos, de forma geral, da Análise do Discurso de linha francesa (AD), dos discursos constituintes, da paratopia, da autoralidade e do hiperenunciador e, no terceiro, procedemos à análise do discurso selecionado, para mostrar o modo como a paratopia desloca a pessoa do evangelista, afasta-o 
do sujeito autor, que gera na subjetividade enunciativa um enunciador, que neutraliza as condições de sua própria criação, ao evocar o hiperenunciador, como a fundamental instância no processo de criação do discurso teológico.

\section{Contextualização do debate}

Nosso esforço de contrapor o discurso religioso ao teológico, com base em uma perspectiva discursiva, conforme Maingueneau $(2008,2010)$, possibilitou-nos uma discussão em torno de seus estatutos. Nessa perspectiva, propusemos uma adequação conceitual, necessária para distinguirmos a constituição desses discursos, destacando alguns elementos ligados à Religião e à Teologia, com o intuito de fundamentar nosso ponto de vista (NASCIMENTO, 2020). Tratar o discurso religioso como institucional, por um lado, e admitir que ele se constitui interdiscursivamente com o teológico tornou-me mais crível, para removê-lo do quadro dos constituintes. Por outro lado, na medida em que o discurso religioso recorre, responsabiliza-se e constrói-se sobre a autoridade do discurso teológico e, por consequência, enuncia-se como discurso segundo, isso confere uma particularidade constituinte ao teológico, garantindo-lhe um status fundante (MAINGUENEAU, 2000). Entretanto, aceitar que o objeto do teológico seja a fé, (LIBANIO, 2005) não compreendida empiricamente, ou como um material bruto, a partir do qual o conhecimento busca organizá-lo, torna-se uma tarefa mais difícil, mas necessária para admitir esse discurso como fundador, inseri-lo no quadro dos constituintes e definir a condição paratópica de seu processo criativo. É lógico pensar, então, que o discurso teológico, como discurso primeiro é o Outro do discurso religioso, mas que o inverso não é possível (MAINGUENEAU, 2005b). 
Quando explicitamos a problemática que incide sobre a categoria discursos constituintes, observamos que Maingueneau (2008, $2009,2010,2012$ ), desde suas primeiras reflexões sobre essa categoria, tem ressaltado que tais discursos, por sua própria natureza, são paratópicos. Sem a pretensão de trazer novamente à discussão a constituência do discurso teológico, nosso empreendimento aqui é, de certa forma, investigar a paratopia no teológico, ou seja, colocá-la em foco e, no mesmo instante, problematizar a especificidade do autor teológico, inserindo o hiperenunciador no campo dos debates sobre esse tipo de discurso. O que nos interessa particularmente, nesse capítulo, é retomar Maingueneau (2010) e considerar sua tese, que postula a paratopia vinculada a um processo criador consciente, que permite o acesso a um não lugar autoral e observarmos como essa categoria produz no escritor do texto teológico uma condição de ser/não ser o criador de seu próprio discurso.

É, como dissemos anteriormente, no âmbito dos constituintes que Maingueneau $(2000,2018)$ reflete sobre a paratopia como uma relação paradoxal de pertencimento e não-pertencimento, que o autor-produtor mantém com a comunidade e o campo discursivo em que ela se inscreve. De maneira mais geral, podemos afirmar que para falar dos discursos constituintes e da condição paratópica desses discursos, Maingueneau (2018) tem dado maior empenho ao estudo do literário, evocando as diferentes atividades de sua produção e de sua inscrição nas práticas sociais de diferentes épocas. Assim, na falta de estudos mais detalhados sobre o discurso teológico, pressupomos que o empenho de Maingueneau pelo discurso literário possa respaldar os demais discursos constituintes. Por isso, apoiamo-nos em pressupostos e análises empreendidas por Maingueneau para a paratopia, no campo discursivo literário, e que chamam a nossa atenção, por exemplo, quando ele nos esclarece que 
A paratopia existe se integrada a um processo criador. $O$ escritor é alguém que não tem um lugar/uma razão de ser (nos dois sentidos da locução) e que deve construir o território por meio dessa mesma falha. Não se trata de uma espécie de centauro que tivesse parte de si mergulhada no peso social e, outra, mais nobre, voltada para as estrelas, mas alguém cuja enunciação se constitui através da própria impossibilidade de atribuir-se a si um verdadeiro lugar que alimenta sua criação do caráter radicalmente problemático de seu próprio pertencimento ao campo literário e à sociedade (MAINGUENEAU, 2018, p. 108).

$\mathrm{Na}$ verdade, Maingueneau engendra a paratopia no processo criador de todos os discursos constituintes, tendo em vista que o escritor ocupa um lugar e um não lugar, fazendo de seu ato criativo um problema de seu próprio pertencimento ao discurso e à sociedade. Assim, construída no/pelo próprio discurso, a paratopia determina haver uma impossibilidade de o sujeito criador atribuir a si mesmo uma posição de autoralidade, que legitime seu real pertencimento ao discurso. Em função disso, presumimos que a autoralidade seja essencial ao funcionamento do discurso pois, assim como o sujeito enunciador, o sujeito autor também se diz e mostra-se a si próprio no discurso. Por isso, podemos afirmar que o autor surge como uma instância presente/ausente no discurso teológico. Ou como afirma Maingueneau (2018, p. 101), o autor não é de fato nem "Ele" nem "EU”, mantendo-se numa irredutível tensão entre os dois.

Além disso, o escritor teológico ocupa/não ocupa o lugar de uma função autoral, mas se abre à emergência de um hiperenunciador, ao deslocar-se de um espaço concreto de pertencimento 
para outro, sem se fixar, constituindo um movimento paratópico. Dessa forma, o

hiperenunciador aparece como uma instância que, por um lado, garante a unidade e a validade da irredutivel multiplicidade dos enunciados do Thesaurus e, por outro, confirma os membros da comunidade em sua identidade pelo simples fato de eles manterem uma relação privilegiada com ele (MAINGUENEAU, 2005, p. 93).

De fato, o processo criativo do discurso teológico pressupõe que o criador não usufrua de um verdadeiro lugar que o legitime como autor, na comunidade discursiva. Ainda mais, a evocação de um sujeito hiperenunciador, na encenação teológica, leva-nos a considerá-lo não apenas responsável por uma enunciação humana, mas também por outra divina, simultaneamente. Assim, certamente, a função do escritor teológico subordina-o à inspiração de Deus e resulta em uma emblemática condição, que torna divino/ humano seu papel criador. Por isso, no ato criativo do texto teológico, o sujeito autor neutraliza-se a si próprio e oculta sua efêmera identidade, mas deixa rastros, para dar vida e voz ao hiperenunciador. Em consequência dessa indecifrável condição, a relação entre o escritor e o hiperenunciador se instaura como uma fronteira, onde eles se cruzam para pôr em funcionamento o discurso.

Outro aspecto que constitui um nó em nosso estudo é que, no percurso das pesquisas de Maingueneau, a categoria de hiperenunciador ainda não mereceu um aprofundamento teórico, que explicite, mais detalhadamente, a sua complexidade. Embora Maingueneau $(2000,2018)$ enfatize a singularidade do ato criador nos discursos constituintes, a organização do teológico exige e ressalta a unidade enunciativa do escritor, do enunciador e do hiperenun- 
ciador. Ou seja, o enunciador unifica a autoralidade teológica, no momento em que relaciona à função autor um hiperenunciador, sujeito transcendente, Jesus, Deus encarnado, a única instância, que garante e valida esse tipo de discurso.

$\mathrm{Na}$ verdade, no discurso teológico, o enunciador investe nele de forma a transparecer uma enunciação, que institui uma disparidade entre os interlocutores, na medida em que o hiperenunciador se enuncia como Absoluto, ou seja, um garante que funda o thesaurus bíblico. Constrói-se, então, um discurso em que o próprio Deus, por meio de Jesus, se institui no discurso como uma verdade de fé incontestável. Nesse caso, fica-nos bem claro que a paratopia se vincula a um processo criador consciente, permite o acesso a um não lugar autoral e produz no autor uma condição de ser e não ser criador de seu próprio discurso.

Parece-nos que o investimento na autoralidade teológica, no código linguageiro e no ethos discursivo realizado pelo enunciador, para organizar a encenação teológica, pode ser um passo adiante para a discussão da categoria inspiração divina proposta pela tradição judaico-cristã. Para nós, um dos pontos cruciais do discurso teológico é o empreendimento teórico, o estatuto epistemológico e a identificação precisa do sujeito hiperenunciador, como aquele que se institui por seu dizer e valida a enunciação teológica. 


\section{Pressupostos teórico-metodológicos}

O ponto de partida teórico-metodológico que sustenta nosso trabalho é da Linguística, mais especificamente, da $\mathrm{AD}$ na abordagem de Maingueneau, que considera uma perspectiva enunciativo-discursiva no tratamento dos diferentes tipos de discursos. Essa abordagem interfere, sobremaneira, na forma de apreensão dos discursos e, de modo particular, o teológico, cujos investimentos ressaltamos as condições sócio-históricas e culturais de sua produção. Tais condições se relacionam à topografia e à cronografia discursivas, à instância sujeito, entendida como todos participantes da enunciação, à autoralidade, função que define uma pessoa e um criador para o discurso, e ao código linguageiro, entendido como as marcas linguísticas, que o enunciador mobiliza na organização do discurso e que, interligados, afiançam e legitimam a atividade enunciativa.

Assim, é por meio dessas categorias que objetivamos mostrar o papel da paratopia e sua relação com a autoralidade teológica, cujo autor produz enunciados vinculados à sua condição de exercício de vida no interior da comunidade discursiva de sua época, sem possibilidade de, na enunciação, atribuí-los para si mesmo. De fato, o escritor teológico imputa a si um lugar extra e intradiscursivo que não é seu, mas de um sujeito hiperenunciador, que se desloca de um espaço simbólico de pertencimento para outro, sem se fixar, constituindo com isso um movimento paradoxal entre o humano e o divino.

Ressaltamos que, segundo a noção de discurso proposta por Maingueneau, é possível apreendermos a Teologia como uma instituição discursiva, por colocar em funcionamento a atividade teológica como prática que organiza o campo discursivo da Teologia. Essa abertura conceitual permite-nos recolocar os textos teológicos nos espaços que os tornaram possíveis, onde eles foram produ- 
zidos, avaliados, administrados (MAINGUENEAU, 2018). Enfim, permite-nos remetê-los à sua historicidade e às suas condições sócio-histórico-culturais e religiosas de produção, o que implica, entre outras coisas, considerar a função do escritor que produz textos teológicos e seu investimento em seu posicionamento.

Antes do mais, vale a pena dizer que a escolha $\mathrm{AD}$, nas perspectivas de Maingueneau, para fundamentar nosso estudo, pareceu-nos a mais adequada. Isso sustenta nossos interesses, na medida em que liga a noção de discurso às suas condições sócio-históricas e culturais de produção, abre-se à interdiscursividade com outros campos do conhecimento, além de apropriar-se de uma concepção de subjetivação enunciativa em que os sujeitos autor, enunciador, co-enunciador e hiperenunciador abarcam conhecimentos, que não só estão em interação, mas também integram a enunciação. Essa abertura proposta por Maingueneau enfoca a subjetividade enunciativa em diferentes dimensões, porque enunciador, autor e hiperenunciador se mobilizam na/pela linguagem e fazem com que a noção de discurso carregue a marca de subjetividade e intersubjetividade.

A perspectiva que aqui assumimos, distanciam-nos, indubitavelmente, da Exegese e da Hermenêutica, haja vista que essas duas disciplinas, grosso modo, objetivam a explicação e interpretação de textos antigos, particularmente, os textos bíblicos. Geralmente, a Exegese é apreendida como uma prática interpretativa e a Hermenêutica como uma teoria da interpretação. Embora, desde sua origem, na década de 60, a tendência interpretativa fuja do escopo da $\mathrm{AD}$, vale retomar que o próprio Pêcheux já havia excluído a possibilidade de a $\mathrm{AD}$ se constituir como uma teoria da interpretação, quando afirma que

A análise do discurso não pretende se instituir em especialista da interpretação, dominando "o" sentido dos 
textos, mas somente construir procedimentos expondo o olhar-leitor a níveis opacos à ação estratégica de um sujeito (tais como a relação discursiva entre sintaxe e léxico no regime dos enunciados, com o efeito do interdiscurso induzido nesse regime, sob a forma do não-dito que aí emerge, como discurso outro, discurso de um outro ou discurso do Outro) (PÊEHEUX, 2002, p. 14).

Com essa afirmação de Pêcheux, observamos que a AD se distancia de uma teoria da interpretação stricto sensu, na medida em que não visa a reconhecer a possibilidade de um sentido estável para o texto a ser descoberto pelo sujeito leitor. Na verdade, a AD não nega a realidade da interpretação; o problema é atribuir ao texto um sentido único, verdadeiro e estabilizado, esquecendo que o sentido sempre pode ser outro (ORLANDI, 2007). Porque há modos de interpretar, a $\mathrm{AD}$ nega uma perspectiva que reconhece a linguagem como tão transparente que não revele uma polissemia dos símbolos e estanque a multiplicidade dos efeitos de sentido. De fato, a AD adota uma perspectiva que integra, no processo de leitura e análise, a historicidade e as condições de produção e recepção dos textos, marcas constitutivas de toda e qualquer materialidade textual. $\mathrm{Na}$ verdade, cabe aos estudos discursivos compreender o modo como o texto negocia efeitos de sentido, reatualizando-os e problematizando-os indefinidamente. Assim, essa perspectiva metodológica afasta-a da Exegese e da Hermenêutica.

Fica claro, portanto, que as reflexões acima justificam nossa opção pela $\mathrm{AD}$, uma vez que a proposta de Maingueneau permite-nos abordar, com profundidade, o discurso teológico, pois considera o sujeito, o código linguageiro e os efeitos de sentido constitutivos dos processos histórico-discursivos, que definem todos os discursos constituintes. Embora Maingueneau (2000) não 
inclua, no quadro dos constituintes, o discurso teológico, em trabalho anterior, Nascimento (2020), justificamos a impossibilidade de inclusão do discurso religioso no quadro dos constituintes, conforme sugerido por Maingueneau. Mas acenamos a necessidade de substituição desse discurso pelo teológico no rol dos constituintes. Nossa recomendação de troca foi possível, somente porque Maingueneau nos dá uma abertura, ao considerar sua proposta de discursos constituintes uma programa preliminar de pesquisa, cuja designação fundamental atesta-os como discursos de origem, tematizam sua própria constituição, estão ligados a uma fonte legitimadora, validada por uma enunciação, que autoriza a si mesma, não possibilitando haver outro tipo de discurso acima deles.

Atentos às discussões em torno da paratopia, percebemos que Maingueneau $(2008,2010,2015 a, 2015 c, 2018)$ refere-se a essa categoria, alocando-a na instância de produção dos discursos constituintes, ou seja, ele a caracteriza como condição desses discursos; por isso, como condição da Teologia como cena englobante. $\mathrm{O}$ fato de Maingueneau postular a paratopia no processo criador, leva-nos a transferi-la para o interior da criação teológica e aliá-la à autoralidade, na medida em que o autor teológico se define por uma subordinação a um sujeito hiperenunciador, que negocia uma localização paradoxal entre o pertencimento e o não pertencimento ao discurso. Assim, com essa concepção, somos levados a considerar, no discurso teológico, o sujeito autor, o enunciador e o sujeito hiperenunciador, que interagem como instâncias enunciativas próprias a esse discurso, pois que uma condição paratópica institui o ato criativo desse tipo de discurso.

Essa condição do constituinte teológico não implica ao hiperenunciador a ausência de lugar, mas uma intricada negociação entre o lugar e não lugar no discurso. Ao inscrever-se na enunciação, o hiperenunciador causa uma tensão e evidencia uma transformação no discurso, mas, ao mesmo tempo, propõe um acordo, 
pois ele é a única instância capaz de validar e legitimar esse tipo de discurso. Trata-se de um apagar/revelar o privilégio do sujeito hiperenunciador para produzir um efeito de verdade à encenação teológica. $\mathrm{O}$ fato de o discurso teológico posicionar-se a respeito da inspiração divina do archeion, considerar o aspecto humano-divino da criação textual, construir identidade para o hiperenunciador confirma a paratopia como processo e produto da criação desse tipo de discurso.

$\mathrm{Na}$ verdade, o que nos interessa na análise do discurso teológico é a inextrincável relação entre o autor, enunciador e o hiperenunciador, instâncias legítimas da enunciação teológica que, de fato, são as criadoras desse tipo de discurso. $\mathrm{O}$ autor do discurso teológico parece ter uma função ameaçada, ou seja, ter e não ter um lugar para ocupar no discurso, pois está preenchido pelo hiperenunciador e vice-versa, pois ambos precisam dar existência ao discurso, revelar as particularidades das condições de enunciação e instaurar efeitos de sentido divino/humano.

Decorre do que antecede que, ao produzir um texto pertencente ao cânon (os textos bíblicos), o sujeito escritor torna-se o porta-voz de um sujeito-hiperenunciador, ou seja, torna-se implicitamente afiançado por um Deus inspirador, que fala e comunica-se com a comunidade discursiva e o mundo. Por essa situação enunciativa, consolida-se a participação dessa instância divina, que leva o escritor a escrever, inspirando-lhe o conteúdo e tornando-o a causa instrumental, que opera na redação do texto advindo de Deus (PRIOTTO, 2019).

Assim, podemos afirmar que Mateus, Marcos e Lucas, ao redigirem o evangelho, aparecem como uma instância autoral, mas que precisam construir um espaço enunciativo por meio de uma condição paratópica, que revele seu pertencimento/não pertencimento ao discurso. Por isso, os enunciados produzidos por aque- 
les sujeitos se movimentam no discurso em meio a uma condição paratópica do ato criativo e impossibilita que, como criadores, se identifiquem como sujeitos efetivamente produtores. Mateus, Marcos e Lucas entendem, por conseguinte, sua produção discursiva como problemática, pois precisam, necessariamente, dar lugar e identidade ao hiperenunciador.

\section{A encenação teológica}

Como nosso estudo se desenvolve no interior da $\mathrm{AD}$, que nos possibilita apreender as relações entre os sujeitos, na análise que segue, examinamos a condição da paratopia criativa no processo de legitimação do discurso teológico. Por amostragem, selecionamos o texto Multiplicação dos pães e dos peixes, um recorte retirado dos três evangelhos sinóticos²: Mateus (14:13-21), Marcos (6:30-44) e Lucas (9:3-15), um dos discursos mais conhecidos entre os relatos da vida de Jesus. Os discursos produzidos por esses escritores são denominados sinóticos por materializarem narrativas comuns, parecidas em sua organização interna, com utilização de superestrutura, interação entre os sujeitos e código linguageiro semelhantes. A Tradição da Igreja Católica entende os evangelhos como os livros mais importantes do Segundo Testamento e como documentos-fonte de conhecimentos sobre Jesus, sua vida, seus ensinamentos e obra (DATLER, 1986).

Pensando agora em termos do modo como Charaudeau (1983, p. 59) entende a enunciação, partimos da premissa de que o aparelho enunciativo pode ser compreendido como um espaço "em que se organizam os lugares dos protagonistas do ato de lingua-

2 Evangelhos sinóticos designam os evangelhos de Mateus, Marcos, Lucas por apresentarem uma mesma visão ou mesmo ponto de vista sobre os acontecimentos da vida e ensinamentos de Jesus, às vezes, com a mesma estrutura. 
gem, em que se definem seu estatuto, se fabrica sua imagem de fala ou se especificam as relações que os unem". Assim, colocando em foco a paratopia criadora, nosso objeto de estudo, refletimos sobre a função do autor teológico e sua complexa relação com o hiperenunciador.

Por se tratar de um discurso em que a encenação se organiza em torno de dizeres de diferentes sujeitos, nossa atenção se delimita à interação paradoxal entre os lugares do sujeito autor, do enunciador e do hiperenunciador. Restringimo-nos às manifestações desses sujeitos e nas relações que os unem, para explicitar a condição paratópica nesse tipo de discurso. Tal delimitação justifica, nesse estudo, a ausência de tratamento do investimento que o discurso assume em relação ao ethos discursivo e mesmo ao código linguageiro, que revela marcas das condições sócio-histórico-culturais e religiosas em que cada texto fora produzido.

Os três textos selecionados sinalizam marcas particulares das realidades onde foram produzidos e de seus co-enunciadores, ou seja, para quem os textos foram escritos. Além disso, vale observar a forma como cada texto expressa a apropriação da cultura, das práticas discursivas de sua época, da cosmovisão de cada autor, e o modo como revelam uma superestrutura semelhante, que testemunha os efeitos condutores do hiperenunciador. Por isso, não há possibilidade de conhecimento dessa instância por uma perspectiva intelectualista, pois ele transcende os processos enunciativos que o envolvem.

Desse modo, no interior desse quadro complexo, compreendemos o código linguageiro como particularizador da visão de mundo de Mateus, Marcos e Lucas, mas reparamos que, associado aos procedimentos de organização discursiva, os autores articulam inconscientemente aspectos da orientação paradoxal do hiperenunciador. A presença desse sujeito inscrito na cenografia 
possibilita-nos integrar os diferentes pontos de vista textualmente marcados, relacioná-los ao sujeito autor e relativizar as diferenças no código linguageiro e não no conteúdo em função das condições sócio-históricas de produção de cada texto.

Como se trata de um texto bíblico, devemos considerar, ainda, a concreticidade do discurso da fé. "A Teologia é sempre um discurso elaborado, dentro de uma realidade concreta, feito em lugar específico com sujeitos e para sujeitos" (PASSOS, 2018). Além disso, o modo como a inspiração divina coloca à prova a função autoral revela os mecanismos que indiciam uma tragicidade paratópica do escritor a um sujeito absoluto e libertador, que valida a enunciação, outorgando sua autoridade transcendente ao discurso. $\mathrm{O}$ que denominamos tragicidade paratópica não significa que o enunciador negue o hiperenunciador ou que ele escape a seu alcance. Ao enunciar, o enunciador constrói a encenação e, com isso, estabelece as regras desse jogo (CULIOLI, apud AUTHIER-REVUZ, 1990).

Em virtude disso, podemos deduzir que essas questões são muito intrincadas e merecem uma análise bem mais ampla do que essa que aqui propomos, na medida em que demandam aprofundamentos teológicos apurados. Como operamos com os constructos a $\mathrm{AD}$, adotamos uma noção de discurso como um espaço onde um sujeito se coloca como referência e mostra a atitude que assume em relação ao que diz, possibilitando uma negociação de efeitos de sentido (MAINGUENEAU, 2015). Nessa perspectiva, apreendemos os evangelhos como discurso teológico, pois consideramos a singularidade da função autoral origem/não origem do processo criativo, posto que seus enunciados são inspirados por um sujeito hiperenunciador de onde o discurso se origina. Por isso, podemos perceber que, nesse tipo de discurso, a autor, sujeito com características psicológicas e sociais, se neutraliza para evidenciar um sujeito Absoluto, que se movimenta na encenação como proble- 
mático de seu próprio pertencimento, pois se manifesta, ao mesmo tempo, nos planos divino e humano.

O que colocamos em problematização é que o processo criador do discurso teológico prevê, necessariamente, o hiperenunciador e as imposições advindas de sua manifestação na encenação. Essas imposturas definem o modo como o texto teológico cria uma complexidade enunciativa, que resulta de uma íntima comunhão entre hiperenunciador, enunciador e o autor, entre a razão e a fé, condições inerentes à prática discursiva teológica. Deus, sujeito hiperenunciador, não priva o autor de sua liberdade, antes a expressão dessa torna-se o sinal paratópico da presença divina no humano (PRIOTTO, 2019). Assim, a paratopia constrói uma incompreensível identidade para o autor, tendo em vista que o hiperenunciador mobiliza um jogo de fala revelador de si mesmo e, simultaneamente, do enunciador, que se coloca presente/ausente no discurso.

O desenvolvimento dessas considerações preliminares à análise permite-nos afirmar a relevância de evocarmos aspectos das condições sócio-históricas de produção dos discursos selecionados, pois que nos dão pistas, que justificam o entendimento de semelhanças na organização e nos pontos de vista assumidos pelos três evangelistas ${ }^{3}$. Buscamos em Ehrman (2013) a informação de que os evangelhos foram escritos no final do século I e que o primeiro a escrever foi Marcos, discípulo de Pedro, entre os anos 65 e 70 d.C. Segundo o autor, Mateus, era publicano, e Lucas, médico e ambos escreveram, posteriormente, cerca de quinze a vinte anos após, entre os anos 90 e 95 d.C. Tais datas, embora situem a produção de cada evangelista, são divergentes entre os estudiosos da Bíblia; todavia podem nos sinalizar que as distâncias espaciais e

3 O evangelho de João é canônico, porém não se enquadra nos sinóticos, pois assume uma organização diferente dos outros. Como objetivamos os sinóticos, não o abordamos aqui, embora o texto da multiplicação dos pães e dos peixes esteja ali também materializado (João 6:1-15). 
temporais das diferentes escritas esclarecem as diferenças estilísticas de cada autor, mas não secundarizam as semelhanças no conteúdo, fruto do mistério da inspiração divina, categoria teológica, antropológica e epistemológica (PRIOTTO, 2019).

É interessante observarmos que as condições sócio-histórico-culturais nos servem de argumento invocado pelo discurso, para particularizar cada um dos evangelistas e comprovar Deus como causa-principal do conteúdo bíblico, e o autor, causa-instrumental da produção do texto (PRIOTTO, 2019). Ressaltamos, ainda, que, conforme Ehrman (2013), os evangelhos foram escritos em grego, língua das práticas de interação social. Mateus escreveu para convencer os judeus de que Jesus era mesmo o Messias, que estava por vir; por isso, escreve na interdiscursividade com o Primeiro Testamento e as profecias a respeito de Jesus. Marcos escreveu, principalmente, para um público gentio, de língua grega e residente do Império Romano. Lucas escreveu, especialmente, para os não gentios, enfatizando a misericórdia de Deus por meio da salvação por Jesus Cristo.

No quadro abaixo, apresentamos os três textos, em paralelo, a fim de observarmos a semelhanças em sua estrutura e destacarmos os enunciados em que há manifestação do sujeito autor e como o hiperenunciador se posiciona na cenografia. 


\begin{tabular}{|c|c|c|}
\hline Mateus 14: 13-21 & Marcos 6: 30-44 & Lucas 9: 10-17 \\
\hline $\begin{array}{l}\text { 13-Jesus, ouvindo isso, } \\
\text { partiu dali, de barco, } \\
\text { para um lugar deserto, } \\
\text { afastado. Assim que } \\
\text { as multidões o soube- } \\
\text { ram, vieram das cida- } \\
\text { des, seguindo-o a pé. } \\
\text { 14-Assim que desembar- } \\
\text { cou, viu uma grande } \\
\text { multidão e, tomado de } \\
\text { compaixão, curou os } \\
\text { seus doentes. 15-Che- } \\
\text { gada a tarde, aproxi- } \\
\text { maram-se dele os seus } \\
\text { discípulos, dizendo: }\end{array}$ & 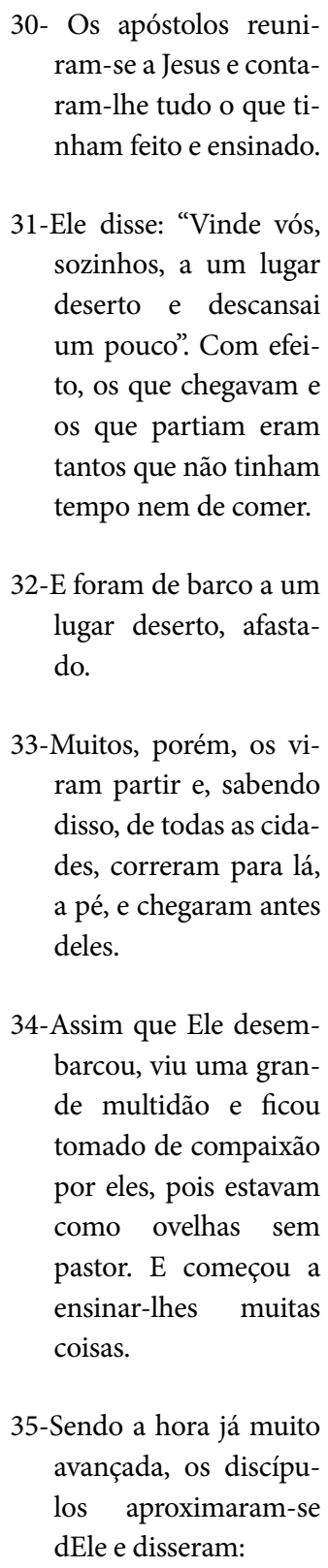 & $\begin{array}{l}\text { 10-Ao voltarem, os após- } \\
\text { tolos narraram-lhe } \\
\text { tudo o que haviam } \\
\text { feito. Tomou-os então } \\
\text { consigo e retirou-se } \\
\text { à parte, em direção a } \\
\text { uma cidade chama- } \\
\text { da Betsaida. 11-As } \\
\text { multidões, porém, } \\
\text { percebendo isso, fo- } \\
\text { ram atrás dele. E, aco- } \\
\text { lhendo-as, falou-lhes } \\
\text { do Reino de Deus e } \\
\text { aos necessitados de } \\
\text { cura restituiu a saúde. } \\
12-\text { O dia começava a } \\
\text { declinar. Aproxima- } \\
\text { ram-se os Doze e dis- } \\
\text { seram-lhe: }\end{array}$ \\
\hline
\end{tabular}




\begin{tabular}{|c|c|c|}
\hline Mateus 14: 13-21 & Marcos 6: 30-44 & Lucas 9: 10-17 \\
\hline $\begin{array}{l}\text { 16-Mas Jesus lhes disse: } \\
\text { "Não é preciso que vão } \\
\text { embora. Dai-lhes vós } \\
\text { mesmos de comer". } \\
\text { 17-Ao que os discípulos } \\
\text { responderam: }\end{array}$ & $\begin{array}{l}\text { "O lugar é deserto e a hora } \\
\text { já muito avançada. } \\
\text { 36-Despede-os para que } \\
\text { vão aos campos e } \\
\text { povoados vizinhos e } \\
\text { comprem para si o que } \\
\text { comer". } \\
\text { 37Jesus lhes respondeu: } \\
\text { "Dai-lhes vós mesmo } \\
\text { de comer". } \\
\text { Tendo-se informado, res- } \\
\text { ponderam: } \\
\text { Disseram-lhe eles: "Ire- } \\
\text { mos nós e compra- } \\
\text { remos duzentos de- } \\
\text { nários de pão para } \\
\text { dar-lhes de comer?" } \\
\text { tos pães tendes? Ide } \\
\text { ver". } \\
\text { ale }\end{array}$ & $\begin{array}{l}\text { "Despede a multidão, para } \\
\text { que vão aos povoados } \\
\text { e campos vizinhos } \\
\text { procurar pousada e } \\
\text { alimento, pois estamos } \\
\text { num lugar deserto". } \\
\text { 13-Ele, porém, lhes disse: } \\
\text { "Dai-lhes vós mesmos } \\
\text { de comer". } \\
\text { Replicaram: }\end{array}$ \\
\hline
\end{tabular}




\begin{tabular}{|c|c|c|}
\hline Mateus 14: 13-21 & Marcos 6: 30-44 & Lucas 9: 10-17 \\
\hline $\begin{array}{l}\text { "Só temos aqui cinco pães } \\
\text { e dois peixes". }\end{array}$ & “Cinco, e dois peixes”. & $\begin{array}{l}\text { 14-Com efeito, eram qua- } \\
\text { se cinco mil homens. } \\
\text { Ele, porém, disse a } \\
\text { seus discípulos: } \\
\text { "Fazei-os acomodar-se } \\
\text { por grupos de uns } \\
\text { cinquenta". 15-Assim } \\
\text { fizeram, e todos se } \\
\text { acomodaram. }\end{array}$ \\
\hline $\begin{array}{l}\text { Disse Jesus: } \\
\text { 18-"Trazei-os aqui". }\end{array}$ & & \\
\hline $\begin{array}{l}\text { 19-E, tendo mandado que } \\
\text { as multidões se aco- } \\
\text { modassem na grama, }\end{array}$ & $\begin{array}{l}\text { 39-Ordenou-lhes lhes en- } \\
\text { tão que fizessem todos } \\
\text { se acomodarem, em } \\
\text { grupos de convivas, } \\
\text { sobre a grama verde. } \\
\text { 40-E sentaram-se no } \\
\text { chão, repartindo-se } \\
\text { em grupos de cem e } \\
\text { de cinquenta. }\end{array}$ & $\begin{array}{l}\text { 16-E tomando os cinco } \\
\text { pães e os dois peixes, } \\
\text { ele elevou os olhos } \\
\text { para o céu, os aben- } \\
\text { çoou, partiu-os e deu } \\
\text { aos discípulos para } \\
\text { que os distribuíssem à } \\
\text { multidão. }\end{array}$ \\
\hline
\end{tabular}




\begin{tabular}{|c|c|c|}
\hline Mateus 14: 13-21 & Marcos 6: 30-44 & Lucas 9: 10-17 \\
\hline $\begin{array}{l}\text { tomou os cinco pães e os } \\
\text { dois peixes, elevou os } \\
\text { olhos ao céu e aben- } \\
\text { çoou. Em seguida, } \\
\text { partindo os pães, deu- } \\
\text {-os aos discípulos, e } \\
\text { os discípulos às mul- } \\
\text { tidões. }\end{array}$ & $\begin{array}{l}\text { 41-Tomando os cinco } \\
\text { pães e os dois peixes, } \\
\text { elevou Ele os olhos ao } \\
\text { céu, abençoou, partiu } \\
\text { os pães e deu-os aos } \\
\text { discípulos para que } \\
\text { lhes distribuíssem. E } \\
\text { repartiu também os } \\
\text { dois peixes entre to- } \\
\text { dos. }\end{array}$ & $\begin{array}{l}\text { 17-Todos comeram e fica- } \\
\text { ram saciados, e foi re- } \\
\text { colhido o que sobrou } \\
\text { dos pedaços: doze } \\
\text { cestos! }\end{array}$ \\
\hline $\begin{array}{l}\text { 20-Todos comeram e fica- } \\
\text { ram saciados, e ainda } \\
\text { recolheram doze ces- } \\
\text { tos cheios dos pedaços } \\
\text { que sobraram. }\end{array}$ & $\begin{array}{l}\text { 42- Todos comeram e fica- } \\
\text { ram saciados. } \\
\text { 43- E ainda recolheram } \\
\text { doze cestos cheios dos } \\
\text { pedaços de pão e de } \\
\text { peixes. }\end{array}$ & \\
\hline $\begin{array}{l}\text { 21-Ora, os que comeram } \\
\text { eram cerca de cinco } \\
\text { mil homens, sem con- } \\
\text { tar mulheres e crian- } \\
\text { ças }\end{array}$ & $\begin{array}{l}\text { 44-E os que comeram dos } \\
\text { pães eram cinco mil } \\
\text { homens. }\end{array}$ & \\
\hline
\end{tabular}

Fonte: BÍBLIA DE JERUSALÉM 
Faz-se necessário atentar à forma como Mateus, Marcos e Lucas se comportam em relação às semelhanças de seus textos. A encenação não se diferencia minimamente em seu conteúdo e isso evidencia que o discurso teológico se organiza em função de um ponto de vista divino/humano engendrado pelo hiperenunciador, que preenche a possível diversidade decorrente dos diferentes espaços/tempos de produção de cada discurso. Embora em espaço e tempo diferentes em sua criação, cada um dos textos busca alcançar os mesmos objetivos e carregam as marcas de uma referência, que produz um efeito paratópico na manifestação de um sujeito produtor. Por isso, a inscrição do criador do discurso teológico ocorre por uma impossibilidade instituída pela inspiração, que concebe o hiperenunciador no plano da fé. Essa reflexão fundamenta o cânon, pois que ele se torna critério prioritário da inspiração; o texto é lido como inspirado porque pertence ao cânon (PRIOTTO, 2019).

Assim, constatamos que os três textos apresentam um tema específico de uma cenografia teológica e organiza a movimentação de enunciados análogos produzidos pelos três escritores. Estamos aqui diante da categoria da inspiração divina, em que Deus, o hiperenunciador, leva o escritor a escrever, inspirando-lhe o conteúdo e imprimindo um efeito de veracidade ao discurso e à obra de Jesus. Essa categoria provém do campo discursivo da Teologia e precisa ser considerada nos estudos do discurso constituinte teológico, pois que ela institui um rigor metodológico exclusivo a esse campo do conhecimento. Essa perspectiva torna-se, categoricamente, necessária para uma leitura negociadora de efeitos de sentido.

Tomamos os três textos como uma unidade e não em suas particularidades enunciativas, para confirmar que o autor do discurso teológico constrói o discurso e institui um sujeito enunciador, que organiza a cenografia em função do hiperenunciador, que problematiza a situação comunicativa, colocando-se em relação ao autor e negociando os efeitos de sentido com base em sua autoridade 
transcendental. Olhemos, por conseguinte, a cenografia e os sujeitos que nela se movimentam, a fim de examinar a paratopia e a forma como ela condiciona a autoralidade teológica e complexifica a tensão com o hiperenunciador. Identificamos, nos três discursos, uma dimensão geográfica, uma dimensão pedagógico-pastoral, uma dimensão humana, uma dimensão divina e uma dimensão interativa, que servem de referência ao conceito de paratopia.

Para produzir enunciados reconhecidos como teológicos, observamos a dimensão geográfica em que esse discurso se instala, mas que não corresponde ao espaço biográfico do escritor, que dele participa, sem pertencer a esse espaço.

\section{Recorte do Texto 1}

Jesus, ouvindo isso, partiu dali, de barco, para um lugar deserto, afastado. Assim que as multidões o souberam, vieram das cidades, seguindo-o a pé. (Mateus)

\section{Recorte do Texto 2}

Os apóstolos reuniram-se a Jesus e contaram-lhe tudo o que tinham feito e ensinado. Ele disse: "Vinde vós, sozinhos, a um lugar deserto e descansai um pouco". (Marcos) 


\section{Recorte do Texto 3}

Ao voltarem, os apóstolos narraram-lhe tudo o que haviam feito. Tomou-os então consigo e retirou-se à parte, em direção a uma cidade chamada Betsaida. (Lucas)

A partir da interação entre Jesus e a multidão, reconhecemos, na dimensão pedagógico-pastoral, todos ouvindo os seus ensinamentos e nele reconhecendo o Reino de Deus acontecendo. Um verdadeiro envolvimento de Jesus com os sofredores, os pobres e os pecadores, para libertá-los de todos os males. Diferente de alguns mestres de seu tempo, Jesus nunca se dirigia para ensinar grupos privilegiados, seus ensinamentos eram para todos os que queriam ouvi-lo. As multidões tinham uma avaliação positiva de Jesus (Ehrman, 2010).

\section{Recorte do Texto 1}

Assim que desembarcou, viu uma grande multidão e, tomado de compaixão, curou os seus doentes. (Mateus)

\section{Recorte do Texto 2}

Assim que Ele desembarcou, viu uma grande multidão e ficou tomado de compaixão por eles, pois estavam como ovelhas sem pastor. E começou a ensinar-lhes muitas coisas. (Marcos) 


\title{
Recorte do Texto 3
}

\begin{abstract}
As multidões, porém, percebendo isso, foram atrás dele. E, acolhendo-as, falou-lhes do Reino de Deus e aos necessitados de cura restituiu a saúde. (Lucas)
\end{abstract}

Embora o discurso em análise, esteja centrado na figura de Jesus, mostra um sujeito preocupado com a multidão, configurando uma dimensão humana. Jesus percebe a fome do povo e a falta de alimentação e opera com sinais que nele identificamos a dualidade humano/divino, traço do hiperenunciador.

Recorte do Texto 1

\begin{abstract}
"O lugar é deserto e a hora já está avançada. Despede as multidões para que vão aos povoados comprar alimento para si". Mas Jesus lhes disse: "Não é preciso que vão embora. Dai-lhes vós mesmos de comer". Ao que os discípulos responderam: "Só temos aqui cinco pães e dois peixes”. Disse Jesus: “Trazei-os aqui”. E, tendo mandado que as multidões se acomodassem na grama. (Mateus)
\end{abstract}




\section{Recorte do Texto 2}

Sendo a hora já muito avançada, os discípulos aproximaram-se dEle e disseram: "O lugar é deserto e a hora já muito avançada. -Despede-os para que vão aos campos e povoados vizinhos e comprem para si o que comer". Jesus lhes respondeu: "Dai-lhes vós mesmo de comer". Disseram-lhe eles: "Iremos nós e compraremos duzentos denários de pão para dar-lhes de comer?” Ele perguntou: "Quantos pães tendes? Ide ver". Tendo-se informado, responderam: "Cinco, e dois peixes". Ordenou-lhes então que fizessem todos se acomodarem, em grupos de convivas, sobre a grama verde. (Marcos)

\section{Recorte do Texto 3}

"Despede a multidão, para que vão aos povoados e campos vizinhos procurar pousada e alimento, pois estamos num lugar deserto". Ele, porém, lhes disse: "Dai-lhes vós mesmos de comer". Replicaram: "Não temos mais que cinco pães e dois peixes; a não ser que fôssemos comprar alimento para todo esse povo". Com efeito, eram quase cinco mil homens. Ele, porém, disse a seus discípulos: "Fazei-os acomodar-se por grupos de uns cinquenta". Assim fizeram, e todos se acomodaram. (Lucas) 
Jesus, com poucos pães e peixes, sacia a multidão e manda recolher a sobra, revelando uma dimensão divina e uma referência ética em sua atitude. $\mathrm{O}$ discurso ancora na perspectiva de que o Reino de Deus se faz presente em sua pessoa e que a multiplicação dos pães e dos peixes deve ser entendida como um sinal de reconhecimento de sua natureza autônoma e transcendental.

\section{Recorte do Texto 1}

Tomou os cinco pães e os dois peixes, elevou os olhos ao céu e abençoou. Em seguida, partindo os pães, deu-os aos discípulos, e os discípulos às multidões. Todos comeram e ficaram saciados, e ainda recolheram doze cestos cheios dos pedaços que sobraram. Ora, os que comeram eram cerca de cinco mil homens, sem contar mulheres $e$ crianças. (Mateus)

\section{Recorte do Texto 2}

Tomando os cinco pães e os dois peixes, elevou Ele os olhos ao céu, abençoou, partiu os pães e deu-os aos discípulos para que lhes distribuíssem. E repartiu também os dois peixes entre todos. Todos comeram e ficaram saciados. E ainda recolheram doze cestos cheios dos pedaços de pão e de peixes. E os que comeram dos pães eram cinco mil homens. (Marcos) 


\section{Recorte do Texto 3}

E tomando os cinco pães e os dois peixes, ele elevou os olhos para o céu, os abençoou, partiu-os e deu aos discípulos para que os distribuíssem à multidão. Todos comeram e ficaram saciados, e foi recolhido o que sobrou dos pedaços: doze cestos! (Lucas)

É na dimensão interativa que nos atemos, mais detalhadamente, na medida em que a compreendemos por meio da encenação teológica, onde os sujeitos se colocam na linguagem e produzem discurso (Benveniste, 2005). Para Maingueneau (2013) a cenografia define a identidade e as relações entre os sujeitos, que nela se movimentam e leva em consideração o lugar e o momento de enunciação. Para nós, o espaço enunciativo é o deserto, e os sujeitos, que ali interagem são o escritor (sujeito empírico e responsável jurídico pelos enunciados), o enunciador (sujeito discursivo), os discípulos, o hiperenunciador e a multidão.

\section{Recorte final}

(AUTOR/ENUNCIADOR) Chegada a tarde, aproximaram-se dele os seus discípulos, dizendo:

(DISCÍPULOS) "O lugar é deserto e a hora já está avançada. Despede as multidões para que vão aos povoados comprar alimento para si".

(AUTOR/ENUNCIADOR) Mas Jesus lhes disse: 
(JESUS) "Não é preciso que vão embora. Dai-lhes vós mesmos de comer".

(AUTOR/ENUNCIADOR) Ao que os discípulos responderam:

(DISCÍPULOS) "Só temos aqui cinco pães e dois peixes". (AUTOR/ENUNCIADOR) Disse Jesus:

(JESUS) “Trazei-os aqui”.

(AUTOR/AUTOR) E, tendo mandado que as multidões se acomodassem na grama, tomou os cinco pães e os dois peixes, elevou os olhos ao céu e abençoou. Em seguida, partindo os pães, deu-os aos discípulos, e os discípulos às multidões. Todos comeram e ficaram saciados, e ainda recolheram doze cestos cheios dos pedaços que sobraram. Ora, os que comeram eram cerca de cinco mil homens, sem contar mulheres e crianças. (Mateus)

Nessa cenografia, o enunciador, responsabilizando-se pela cenografia, apresenta-se a si próprio e, ao colocar em movimento os sujeitos, neutraliza o autor, tornando-se protagonista, na medida em que assume a palavra e dá voz, aos discípulos e ao hiperenunciador. O sujeito hiperenunciador, mesmo sendo da ordem do divino/humano e tendo o poder de comandar o dizer, não o faz e delimita seus próprios limites, a fim de possibilitar a eficácia da enunciação teológica pela objetividade da interação. Por isso, não é ele quem assume o comando do discurso, mas ocupa um lugar central e submete-se ao jogo do enunciador, que o situa ao lado dos outros sujeitos, compartilhando seus enunciados. Institui, assim, um paradoxo entre o autor, o enunciador e o hiperenunciador, esse 
um sujeito que transita em um espaço problemático e misterioso, condição fundamental da encenação teológica.

O sujeito autor/enunciador enuncia por meio de discurso direto, com o intuito de dar autenticidade e espontaneidade aos enunciados dos diferentes sujeitos. Essa estratégia, nesse tipo de discurso, torna-se uma condição, pois possibilita que o autor/enunciador se distancie do processo criador do discurso, garanta uma unidade textual, outorgando ao hiperenunciador aquilo que é dito na cenografia. Por isso, nosso empreendimento analítico realça a interação dos sujeitos autor/enunciador/hiperenunciador, porque esses sujeitos se reconhecem, intra e extradiscursivamente, enriquecendo o efeito de verdade que estabelecem entre eles. Tal reconhecimento permite-nos delimitar em suas formas de interlocução um processo paratópico. O enunciador, mesmo representando papel de autor, vê-se legitimado pelo hiperenunciador.

No recorte acima, observamos os sujeitos se movimentando na cenografia, mas, na verdade, vemos uma função autoral e um ethos discursivo que, por um comportamento de subordinação a um sujeito hiperenunciador, negociam uma localização paradoxal entre o pertencimento e o não pertencimento ao discurso.

\section{Conclusão: uma reflexão constante}

Ao longo desse capítulo, refletimos sobre a paratopia, a autoralidade teológica e a complexa relação com o sujeito hiperenunciador, cuja movimentação subjetiva se manifesta linguisticamente. Estudar a condição paratópica do escritor do discurso teológico não é uma tarefa fácil, pois instaura uma difícil problemática, ao colocar na cena um sujeito Absoluto. Mais do que um sujeito entre 
os outros, o hiperenunciador assume um papel transcendental e ao mesmo tempo paradoxal, ao demarcar-se no espaço discursivo do humano e do divino. Embora não fosse nosso objetivo aprofundar a natureza do hiperenunciador, para integrá-lo na cenografia, tivemos que recorrer à categoria de inspiração divina, já que nossa proposta exigiu um diálogo epistêmico e interdisciplinar com o campo da Teologia. A concepção de um sujeito autor independente, desligado de um sujeito transcendente, pareceu-nos não ser possível na organização do discurso teológico.

O ponto de partida teórico-metodológico que fundamentou nosso estudo foi da Linguística, mais especificamente, da $\mathrm{AD}$ na abordagem de Maingueneau, que considera uma perspectiva enunciativo-discursiva no tratamento dos diferentes tipos de discursos. Esse posicionamento que nos possibilitou relacionar a $\mathrm{AD}$ com a Teologia correspondeu à necessidade de entrelaçar uma epistemologia das ciências da linguagem com outra da fé, fundamental para dar conta de nossos objetivos.

A escolha dos discurso Multiplicação dos pães e dos peixes, escritos por Mateus, Marcos e Lucas possibilitou-nos a interdisciplinaridade da $\mathrm{AD}$ com a Teologia e, mais do que isso, levou-nos à compreensão da forma como a encenação teológica resulta do trabalho criativo do autor pelo qual o enunciador se representa e manifesta o hiperenunciador. Com isso, pode-se afirmar que há uma indissociabilidade entre esses sujeitos e a forma linguística como enunciam

Nossa reflexão enfatizou a condição paratópica do processo criador do discurso teológico; entretanto, no decorrer do trabalho, percebemos que a análise dessa categoria não poderia estar totalmente equacionada. O próprio Maingueneau (2000), desenvolvendo seus estudos sobre discursos constituintes e de sua condição paratópica, preveniu-nos que sua hipótese sobre discursos consti- 
tuintes e sua condição paratópica estava apenas projetada. É nesse contexto que colocamos a categoria de hiperenunciador, instância ainda não aprofundada em estudos mais detalhados, que nos propiciem orientações mais amplas de suas funções no discurso.

Desde o início desse trabalho, identificamos as limitações de nosso empreendimento, principalmente pelas imposturas que definem o modo como o texto teológico cria uma complexidade enunciativa, que resulta de uma indissociabilidade, ou seja, uma comunhão entre autor, enunciador e hiperenunciador, entre a razão e a fé, condições inerentes à prática discursiva teológica. Como autor, enunciador e hiperenunciador participam da cenografia, cada um desses sujeitos, por meio de seus atos de dizer, interagem na encenação teológica e deixam marcas de sua interação.

Embora Maingueneau enfatize a singularidade do ato criativo nos discursos constituintes, a organização e o funcionamento do discurso teológico neutralizam a autoralidade na produção do discurso e salientam sua representação enunciativa, a partir de uma identidade assumida por um hiperenunciador, Jesus, Deus encarnado, única instância, que garante e valida esse tipo de discurso. Essa questão fundamental, ainda que seja específica do campo da Teologia permeia aquelas abarcadas pela Linguística, pois envolve a materialidade linguística e a questão da subjetividade. Na verdade, a $\mathrm{AD}$ e a Teologia apoiam-se na linguagem e marcam suas identidades por seus conteúdos e por meio de perspectivas histórico-culturais específicas de cada campo discursivo.

Ao finalizar essa etapa desse trabalho, sinalizamos que, ao colocarmos em foco a paratopia, trouxemos, também, a problematização da especificidade da enunciação teológica para as discussões sobre os discursos constituintes, conforme proposto por Maingueneau. Além disso, compreender a função autoral do produtor desse tipo de discurso, leva-nos à necessidade de aprofundar estudos 
sobre a manifestação enunciativa do hiperenunciador e a forma como ele se constitui a si próprio como sujeito e seus efeitos sobre o discurso e seu produtor.

A análise que empreendemos mostrou que a paratopia se vincula a um processo criador consciente, permite o acesso a um não lugar autoral e produz no escritor do texto teológico uma condição de ser e não ser o criador de seu próprio discurso. $\mathrm{O}$ investimento na função autoral, na cenografia teológica, é um tema para a ampliação do debate sobre o discurso teológico como constituinte, do potencial discursivo da Teologia e da rediscussão da categoria da inspiração bíblica, conforme proposto no campo teológico.

\section{Referências}

AUTHIER-REVUZ, Jacqueline. Heterogeneidade(s) Enunciativa(s). Cadernos de Estudos Linguísticos, (19) 25-42, julho/dezembro, Campinas, 1990.

BENVENISTE, Émile. Problemas de linguística geral I. São Paulo: Nacional, 2005.

BÍBLIA de Jerusalém - Nova edição, revista e ampliada 3. imp. São Paulo: Paulus, 2006.

CHARAUDEAU, P. Langage et Discours: éléments de sémiolinguistique. Paris: Hachette, 1983.

COSSUTTA, Frédéric. Elementos para a leitura dos textos filosóficos. São Paulo Martins Fontes, 1994.

CULIOLI, Antoine. Conditions d'utilisation des données issues de plusieurs langues naturelles. Pour une linguistique de l'énonciation: formalisation et opérations de repérage. $\mathrm{Pa}$ ris: Ophrys, 1999. v. 2, p. 67-82.

DATLER, Frederico. Sinopse dos Quatro Evangelhos. São Paulo: Paulus, 1986. 
EHRMAN, B. D. Problema com Deus: as respostas que a Bíblia não dá ao sofrimento. Rio de Janeiro: Agir, 2008.

EHRMAN, B. D. Quem foi Jesus? Quem não foi Jesus? Rio de Janeiro: Pocket Ouro, 2010.

EHRMAN, B. D. Quem escreveu a Bíblia? Rio de Janeiro: Agir, 2013.

FOUCAULT, Michel. O que é um autor? Lisboa: Vega, 2002.

GABUS, Jean-Paul. Critique du discours théologique. Paris: Delachaux \& Niestlé, 1977.

LIBANIO, João Batista \& MURAD, Afonso. Introdução à teologia - perfil, enfoques, tarefas. São Paulo: Loyola, 2005.

MAINGUENEAU, Dominique. O contexto da obra literária. São Paulo, Martins Fontes, 1995a.

MAINGUENEAU, Dominique. L'énonciation philosophique comme institution discursive. In: Langages, ano 29, n. 119, 1995b.

MAINGUENEAU, Dominique. Pressupostos e subentendidos. In: Pragmática para o discurso literário. São Paulo: Martins Fontes, 1996.

MAINGUENEAU, Dominique. L'analyse des discours constituants. In: MARI, Hugo et al. (orgs.). Fundamentos e dimensões da análise do discurso. Belo Horizonte: Carol Borges, 1999.

MAINGUENEAU, Dominique. Analisando discursos constituintes. Revista do GELNE, Natal, RN, v. 2, n. 2, p. 1-12, 2000.

MAINGUENEAU, Dominique. A noção de hiperenunciador. Trad. Roberto Leiser Baronas e Fábio César Montanheiro. Polifonia, n. 10, p. 75-97, Cuiabá, 2005a.

MAINGUENEAU, Dominique. Gênese dos discursos. São Paulo: Criar, 2005b. 
MAINGUENEAU, Dominique. Análise do discurso e suas fronteiras. Matraga, Rio de Janeiro, v. 14, n. 20, p. 13-37, jan./jun. Rio de Janeiro, 2007.

MAINGUENEAU, Dominique. Cenas da enunciação. São Paulo: Parábola, 2008.

MAINGUENEAU, Dominique. La difficile émergence d'une analyse du discours religieux, Langage et société, 4, n. 130, 2009.

MAINGUENEAU, Dominique. Doze conceitos em Análise do Discurso. São Paulo: Parábola, 2010.

MAINGUENEAU, Dominique. Clareza do texto, discursos constituintes e quadro hermenêutico. Revista do Programa de Pós-Graduação em Letras da Universidade de Passo Fundo - v. 8, n. 1, pp. 11-19, jan./jun. 2012.

MAINGUENEAU, Dominique. Discurso e análise do discurso. São Paulo: Parábola, 2015a.

MAINGUENEAU, Dominique. O que pesquisam os analistas do discurso. Revista da ABRALIN, v. 14, n. 2, p. 31-40, jul./ dez. 2015b.

MAINGUENEAU, Dominique. La Philosophie comme instituition discursive. Limonges: Lambert-Lucas, 2015c.

MAINGUENEAU, Dominique. Retorno crítico sobre o ethos. In: BARONAS, Roberto Leiser. MESTI, Paula Camila; CARREON, Renata de Oliveira. Análise do Discurso: entorno da problemática do ethos, do político e de discursos constituintes. Campinas, SP: Pontes, 2016a, pp. 13-33.

MAINGUENEAU, Dominique. Autoralidade e Pseudonomia. Revista da ABRALIN, v. 15, n. 2, p. 101-117, jul./dez. 2016 b.

MAINGUENEAU, Dominique. O discurso literário. $2^{\mathrm{a}}$ ed., $2^{\text {a }}$.reim, São Paulo: Contexto, 2018.

MAINGUENEAU, Dominique \& COSSUTTA Frederic. Lanalyse des discours constituants. Langages, n. 29, pp. 112-125, 
Paris, 1995.

MEEKS. Wayne. O mundo moral dos primeiros cristãos. São Paulo: Paulus, 1996.

NASCIMENTO, Jarbas Vargas. O discurso teológico como discurso constituinte. In: NASCIMENTO, Jarbas Vargas \& FERREIRA, Anderson. Discursos constituintes. São Paulo: Blucher, 2020.

ORLANDI, Eni Pulchinelli. Interpretação, autoria, leitura e trabalho simbólico. $3^{\text {a }}$.ed. Campinas: Pontes, 2007.

PASSOS, João Décio. Método Teológico. São Paulo: Paulinas, 2018.

PÊCHEUX, Michel. O discurso: estrutura ou acontecimento. Trad. Eni Puccinelli Orlandi,3ª ed. Campinas: Pontes, 2002.

PRIOTTO, Michelangelo. Introdução Geral às Escrituras. Petrópolis, RJ: Vozes, 2019. (Introdução aos Estudos Bíblicos).

SCHLEIERMACHER, Friedrich D.E. Hermenêutica: arte e técnica da interpretação. 5.ed.Trad. Celso Reni Braida. Bragança Paulista: Universitária São Francisco, 2006.

SCHLEIERMACHER, Friedrich D.E. Hermenêutica e crítica. Trad. Aloísio Ruedell. Ijuí: EUnijuí, 2005.

SCHLEIERMACHER, Friedrich D.E. Hermenêutica: arte e técnica da interpretação. Petrópolis: Vozes. 1999.

SCHNELLE, Udo. Introdução à Exegese do Novo Testamento. São Paulo: Loyola, 2004. 